\title{
Is Ridge Cultivation Sustainable? A Case Study from the Haean Catchment, South Korea
}

\author{
Marianne Ruidisch, ${ }^{1}$ Sebastian Arnhold, ${ }^{1}$ Bernd Huwe, ${ }^{1}$ and Christina Bogner ${ }^{2}$ \\ ${ }^{1}$ Soil Physics Group, BayCEER, University of Bayreuth, 95440 Bayreuth, Germany \\ ${ }^{2}$ Ecological Modelling, BayCEER, University of Bayreuth, Dr.-Hans-Frisch-Straße 1-3, 95448 Bayreuth, Germany
}

Correspondence should be addressed to Marianne Ruidisch; ruidisch@uni-bayreuth.de

Received 11 May 2013; Accepted 11 September 2013

Academic Editor: John Crawford

Copyright (C) 2013 Marianne Ruidisch et al. This is an open access article distributed under the Creative Commons Attribution License, which permits unrestricted use, distribution, and reproduction in any medium, provided the original work is properly cited.

\begin{abstract}
Non-sustainable agricultural practices can alter the quality of soil and water. A sustainable soil management requires detailed understanding of how tillage affects soil quality, erosion, and leaching processes. Agricultural soils in the Haean catchment (South Korea) are susceptible to erosion by water during the monsoon. For years, erosion-induced losses have been compensated by spreading allochthonous sandy material on the fields. These anthropogenically modified soils are used for vegetable production, and crops are cultivated in ridges using plastic mulches. To evaluate whether the current practice of ridge cultivation is sustainable with regard to soil quality and soil and water conservation, we (i) analysed soil properties of topsoils and (ii) carried out dye tracer experiments. Our results show that the sandy topsoils have a very low soil organic matter content and a poor structure and lack soil burrowers. The artificial layering induced by spreading sandy material supported lateral downhill water flow. Ridge tillage and plastic mulching strongly increased surface runoff and soil erosion. We conclude that for this region a comprehensive management plan, which aims at long-term sustainable agriculture by protecting topsoils, increasing soil organic matter, and minimizing runoff and soil erosion, is mandatory for the future.
\end{abstract}

\section{Introduction}

Ecosystem services and agriculture are closely related and affect each other. On the one hand, ecosystems used for agriculture produce food, reduce hunger, and improve public health-services that become more and more important in view of a growing world population. On the other hand, agricultural mismanagement can reduce the ability of ecosystems to provide these goods and services $[1,2]$.

Soils play a key role in providing supporting and regulating services such as soil fertility, soil retention, nutrient cycling, and carbon sequestration [3]. Appropriately managed soils in agricultural ecosystems can contribute to soil and water conservation [4], while poorly managed systems may deteriorate ecosystem services by high nutrient and sediment losses from agricultural fields. Possible consequences are soil degradation, declining water quality, water pollution, and increasing costs for water purification $[5,6]$. The major goal in agriculture is therefore a sustainable management that minimizes the risk of soil and environmental degradation [7] and at the same time ensures improved yields and ecosystem services [2].

Agricultural production in South Korea faces an enormous pressure due to its limited arable land of about $22 \%$ of the total area [8]. To increase yields, forested areas on hillslopes have been converted to agricultural land and the application of chemical fertilisers has increased from $230 \mathrm{~kg} \mathrm{ha}^{-1}$ year $^{-1}$ in 1980 to $450 \mathrm{~kg} \mathrm{ha}^{-1}$ year $^{-1}$ in 1994 [9]. These high fertiliser rates in combination with heavy rainfall events during the East Asian summer monsoon are critical in relation to water pollution and eutrophication. Actually, eutrophication of water reservoirs has become a widely recognized problem in South Korea. Especially the transport of applied phosphorus with sediments in surface runoff during monsoon events considerably affects the water resources [9-11]. Therefore, in monsoon regions, an appropriate agricultural management to decrease soil and environmental degradation is particularly important. 
To determine the pathways of agricultural pollutants and sediments, we have to identify the impact of agricultural practices on water flow on the soil surface as well as in the soils. In general, there are quite different flow phenomena in the soils. Water can percolate slowly through the soil matrix (uniform flow) or it can move rapidly through preferred pathways and bypass a fraction of the porous soil matrix. This preferential flow can occur in root channels, earthworm burrows, fissures or cracks (macropore flow), or along textural boundaries (funnel flow) [12]. Preferential flow is responsible for a rapid water movement and solute transport to greater soil depths or groundwater [13-15]. Its occurrence in soils depends on soil texture, soil structure, topography, surface microrelief, and management as well as on the initial soil water content and the intensity and duration of rainfall $[16,17]$.

In South Korea, the distribution of allochthonous soil material on dryland fields has become a widespread method to compensate the erosion-induced soil loss. Although this method has recently been prohibited by the government, the artificial layering induced by this practice still persists in the soil profiles. To our knowledge, the influence of this management practice on the water flow in soils has never been investigated. On most of these anthropogenically modified dryland fields, crops are cultivated in ridge tillage systems using plastic mulch. Ridge tillage and plastic mulching were found to have positive effects on crop yield and weed control [18]. However, their effects on water flow, solute, and sediment transport have rarely been investigated.

The aim of our study is to evaluate whether the current practice of ridge cultivation in the Haean catchment in South Korea is sustainable. We focus on soil quality and soil and water conservation. Therefore, we (i) analysed the soil properties of the anthropogenically modified topsoils from various dryland fields distributed over the Haean catchment. Additionally, to (ii) qualitatively describe the effects of tillage on flow patterns and to (iii) quantify surface runoff and soil erosion, we carried out four dye tracer experiments under flat conventional tillage, ridge tillage, ridge tillage with plastic mulch, and ridge tillage with plastic mulch cropped with potato plants.

\section{Materials and Methods}

\subsection{Study Site}

2.1.1. General Description. The Haean-myun catchment $\left(128^{\circ} 1^{\prime} 33.101^{\prime \prime} \mathrm{E}, 38^{\circ} 28^{\prime} 6.231^{\prime \prime} \mathrm{N}\right)$, also called "the Punchbowl," is located in the mountainous northeastern part of South Korea and has a total area of approximately $64 \mathrm{~km}^{2}$. The characteristic bowl-shaped topography subdivides the catchment into three major land use zones. The steep hillslopes are mostly forested (58\%), moderate slopes at the forest edges are dominated by dryland farming (22\%), and rice paddies $(8 \%)$ are characteristic for the flat central area of the catchment. The remainder is occupied by residential areas, grassland, field margins, and farm roads.

The annual precipitation in the Haean catchment equals $1599 \mathrm{~mm}$ (13-year average from 1999 to 2011) with more than
$60 \%$ of the annual rainfall occurring during the monsoon season from June to August. The annual temperature averages $8.5^{\circ}$, ranging from $-6.8^{\circ}$ in January to $21.5^{\circ}$ in July (13-year monthly averages from 1999 to 2011).

The bedrock in the catchment is made up mainly of granite which is strongly weathered due to the high precipitation rates. It constitutes the parent material for Cambisols-the most widely spread soil type in the study area.

2.1.2. Agricultural Practice on Dryland Fields. The dominant agricultural practice for row crops on Korean dryland fields is ridge tillage with polyethylene covers (plastic mulch) (Figure SF4 in the Supplementary Material available online at http://dx.doi.org/10.1155/2013/679467). The black plastic cover helps to control weeds and to induce an earlier plant emergence due to higher temperature underneath. Additionally, the cultivation in ridges facilitates harvesting.

At the beginning of the growing season, between April and May (depending on the crop type), a granulated mineral fertiliser is applied, fields are ploughed, and the fertiliser is mixed into the top soil. Subsequently, ridges (approximately $15 \mathrm{~cm}$ high and $30 \mathrm{~cm}$ wide) are created primarily perpendicular to the main slope direction with approximately $70 \mathrm{~cm}$ spacing. The ridges are covered with black polyethylene sheets perforated with $25-30 \mathrm{~cm}$ spaced planting holes $(5 \mathrm{~cm}$ diameter), while furrows between ridges remain uncovered. After ridges and furrows are created, depending on the crop type, seeds are sown or juvenile plants are planted into the planting holes. Several times during the growing season, herbicides and pesticides are applied, and mineral fertilisers are spread a second time on the fields, depending on the crop type. Finally, harvesting begins usually between August and September.

The main row crops cultivated on dryland fields are cabbage, radish, potato, and beans $[19,20]$. Because of their low ground cover, especially in early growth stages, fields with row crops are more susceptible to soil erosion by water than other fields [21]. Therefore, as a consequence of extreme rainfall events during the summer monsoon, many dryland field soils in the Haean catchment have been highly degraded. In order to compensate these erosion losses, farmers used to distribute sandy material from nearby mountain slopes on their fields [22] (Figure SF5 in the online Supplementary Material). The distribution of allochthonous material in the past and repeated ploughing generated irregular artificially layered soil profiles on many dryland fields. Thus, frequently, the topsoil and the subsoil have distinct physical and chemical properties.

\subsection{Field Work}

2.2.1. Sampling of Topsoils on Agricultural and Forest Sites. In 2009, we took samples of topsoils on 32 dryland fields and on 16 forest sites in the Haean catchment. The dryland fields included the four major crops cultivated in the catchment, namely, cabbage, radish, potato, and bean fields. At each agricultural site, five samples (from the four corners and the center of the field) were taken and mixed together. After 
TABLE 1: Soil physical properties of the experimental sites.

\begin{tabular}{|c|c|c|c|c|c|c|c|}
\hline & Horizon (WRB) & Depth $^{\mathrm{a}}(\mathrm{cm})$ & Clay (\%) & Silt (\%) & Sand (\%) & Soil texture class & Bulk density $\left(\mathrm{g} \mathrm{cm}^{-3}\right)$ \\
\hline \multirow{3}{*}{ Site 1} & Ap & $0-25$ & 3.2 & 16.4 & 80.3 & Loamy sand & 1.43 \\
\hline & $2 \mathrm{Apb}^{\mathrm{b}}$ & $25-50$ & 20.2 & 53.4 & 26.4 & Silt loam & 1.45 \\
\hline & Bwb & $50-100$ & 24.8 & 46.6 & 28.6 & Loam & 1.38 \\
\hline \multirow{5}{*}{ Site 2} & Ap1 & $0-35$ & 1.9 & 14.5 & 83.6 & Loamy sand & 1.41 \\
\hline & Ap2 & $35-45$ & 8.1 & 28.9 & 63.0 & Sandy loam & 1.66 \\
\hline & Ap3 & $45-55$ & 7.6 & 27.9 & 64.5 & Sandy loam & 1.61 \\
\hline & $2 \mathrm{Apb}$ & $55-70$ & 20.9 & 58.2 & 20.9 & Silt loam & 1.28 \\
\hline & 2Bwb & $70-100$ & 13.6 & 38.9 & 47.5 & Loam & 1.56 \\
\hline
\end{tabular}

${ }^{\mathrm{a}}$ Approximate depth, ${ }^{\mathrm{b}}$ horizon continuous in the second experiment (RT) only.

sampling, soil texture, $\mathrm{C}, \mathrm{N}$ and soil organic matter (SOM) were analysed in the laboratory.

2.2.2. Dye Tracer Experiments. In 2010, we carried out four irrigation experiments at two potato fields (Solanum tuberosum L.) on hillslopes. Field site $1\left(128^{\circ} 6^{\prime} 32.625^{\prime \prime} \mathrm{E}\right.$, $38^{\circ} 18^{\prime} 4.148^{\prime \prime} \mathrm{N}$ ) was located in a distance of approximately $830 \mathrm{~m}$ from field site $2\left(128^{\circ} 6^{\prime} 54.803^{\prime \prime} \mathrm{E}, 38^{\circ} 17^{\prime} 43.254^{\prime \prime} \mathrm{N}\right)$. Both soils can be characterized as anthropogenically modified Cambisols with eroded A-horizons. Allochthonous sandy soil material was spread several times on top of the fields. The soils were classified as a Terric Cambisol and a Terric Anthrosol over Haplic Cambisol [23] with a slope of $8^{\circ}$ and $6^{\circ}$ on field sites 1 and 2 , respectively. We selected these fields because their slope degrees and soil physical properties were comparable (Table 1).

We carried out the first two experiments on field site 1 and the last two on field site 2. The first experiment (CT) took place after ploughing and before ridges were created, so that the soil surface was flat and represented conventional tillage. The second one (RT) was carried out after the creation of ridges. At field site 2, potato crops were planted in ridges covered with black plastic mulch, and we conducted the third experiment $\left(\mathrm{RT}_{\mathrm{pm}}\right)$ in the early season when the potatoes were just sown. Finally, the last irrigation experiment $\left(\mathrm{RT}_{\mathrm{pm}+\mathrm{crops}}\right)$ was carried out at the same field site as the experiment $\mathrm{RT}_{\mathrm{pm}}$ but later in the growing season, when potato crops and their root systems were already well developed. In the following we use CT, $\mathrm{RT}, \mathrm{RT}_{\mathrm{pm}}$, and $\mathrm{RT}_{\mathrm{pm}+\mathrm{crops}}$ to refer to the corresponding experiments, plots, or tillage.

Before irrigation, we installed FDR soil moisture sensors (Decagon devices, Inc., Pullman, WA 99163, USA) to monitor the volumetric water content $\theta_{V}$. On CT, they were placed in 5 and $20 \mathrm{~cm}$ depth from the flat soil surface. In experiments $\mathrm{RT}$ and $\mathrm{RT}_{\mathrm{pm}}$, two sensors were situated in furrows in 5 and $20 \mathrm{~cm}$ depth from the furrow surface and another two in ridges in 5 and $20 \mathrm{~cm}$ depth from the ridge surface. Due to technical problems, the fourth experiment was carried out without soil moisture sensors. We recorded the values of soil moisture in a 2-minute interval on a data logger (Decagon devices, Inc., Pullman, WA 99163, USA).

We irrigated a surface of $2 \mathrm{~m}^{2}$ with a tracer solution containing $5 \mathrm{~g} \mathrm{~L}^{-1}$ of Brilliant Blue FCF using an automated sprinkler. Because this tracer can be retarded compared to the infiltrating water [24], we added $5 \mathrm{~g} \mathrm{~L}^{-1}$ potassium iodide on plots $\mathrm{CT}$ and $\mathrm{RT}_{\mathrm{pm}}$ as a reference tracer. To measure the amount of surface runoff and the sediment load, the irrigation area was equipped with an infiltration frame. It channelled the surface runoff and the sediments via internal tubes into buckets outside of the frame. After the experiment we measured the water level in the buckets. We took homogenized samples of water with sediment, dried them in a drying oven, and weighed the sediment. The total time and amount of irrigation varied among experiments due to technical problems with blocked sprinkler jets. However, the experiments were still comparable (Table 3 ).

One day after the irrigation we excavated 8-10 soil profiles of $1 \times 2 \mathrm{~m}$ spaced by $10 \mathrm{~cm}$ on each plot. For visualization of the iodide tracer, an indicator solution with iron(III) nitrate and starch was prepared [25] and sprayed onto the excavated soil profiles. All profiles were equipped with a metallic frame of $2 \mathrm{~m}^{2}$ and a Kodak color scale and photographed with a digital single lens reflex camera (Canon EOS 1000D). Only the parts of the profiles surrounded by the frame were analysed.

The soil profiles were sampled to determine soil physical properties. We carefully scraped soil material from different profiles and analysed the texture in a laser particle size analyzer (Mastersizer S "MAM 5044," Malvern instruments $\mathrm{GmbH}$, Herrenberg, Germany). Additionally, we took undisturbed samples with small soil core rings (diameter $2.8 \mathrm{~cm}$, height $1 \mathrm{~cm}$ ) in different horizons. They were weighed, dried for 24 hours at $105^{\circ} \mathrm{C}$ in a drying oven, and weighed again to calculate the bulk density.

\subsection{Data Analysis}

2.3.1. Image Processing. We corrected the images for perspective and radial distortion such that they corresponded to pictures taken by an ideal camera looking perpendicularly onto the profiles. The transformation was calculated by

$$
\vec{v}=\frac{1}{1+\kappa \cdot\langle\vec{u}, \vec{u}\rangle} \cdot \vec{u},
$$

where the parameter $\kappa$ is the magnitude of the radial distortion, $\vec{u}$ are coordinates of a point in the original image, $\vec{v}$ are coordinates in the corrected one, and the brackets \langle\rangle indicate the inner product. If $\kappa$ is negative, the distortion is barrel 


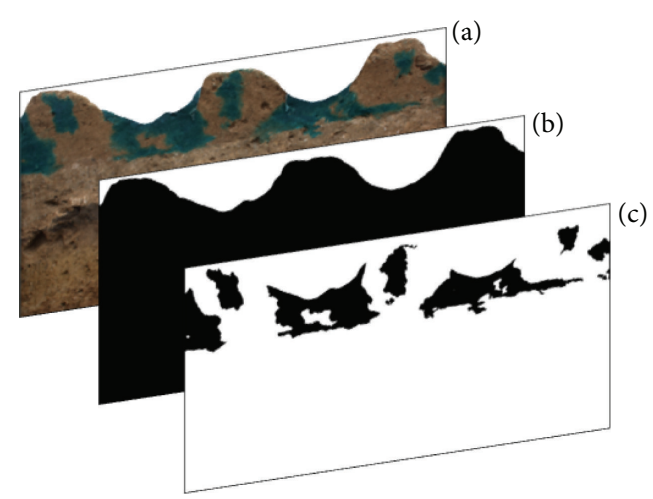

FIgURE 1: Processing of images of dye-stained soil profiles: (a) rectified dye tracer image, (b) background image with the soil coded black and the background between ridges white, and (c) final binary image used to calculate image indices with dye-stained pixels coded black and nonstained ones coded white.

shaped, while for positive $\kappa$ it is pincushion shaped [26]. The parameter $\kappa$ is obtained in a camera calibration procedure with a special calibration plate.

Subsequently, we transformed the images from RGB to HSI (hue, saturation, intensity) color space and classified the pixels into Brilliant Blue stained (black) and nonstained (white) ones to obtain binary images. The transformation is necessary because the HSI color space is more suitable for color-based segmentations of images taken under varying illumination. More details on image transformation and classification are given in Bogner et al. [13].

For the experiments RT, $\mathrm{RT}_{\mathrm{pm}}$, and $\mathrm{RT}_{\mathrm{pm}+\text { crops }}$ we additionally produced a second binary background image, where the soil was coded black and the background between ridges white (Figure 1). The correction of distortion and color segmentation were done in Halcon ver. 10.0 (MVTec Software $\mathrm{GmbH}$, Munich, Germany).

2.3.2. Image Index Functions. We used the binary images to assess differences between the tillage management systems. The first two experiments (CT and RT) show the influence of soil surface topography on flow patterns in general. By comparing the experiments $\mathrm{RT}$ and $\mathrm{RT}_{\mathrm{pm}}$, we can infer the effect of plastic mulch. Finally, we can extract information about the impact of the potato canopy and root system on flow patterns by comparing the images of $\mathrm{RT}_{\mathrm{pm}}$ with those of $\mathrm{RT}_{\text {pm+crops }}$.

To effectively analyse the flow patterns in binary images, we calculated image index functions or simply indices. An index is a real-valued function of a binary vector $\vec{r}$ of size $m$ (i.e., a row in a binary image of width $m$ ) [27]. These functions are constructed such that they are independent of the size of the image and confined to the interval $[0,1]$. They extract different features of a binary image row by row. Actually, because the vertical direction is the primary direction of water movement in the vadose zone, these functions summarize the horizontal and emphasize the vertical configuration of patterns. For a detailed mathematical description see Trancón y Widemann and Bogner [27] who we follow closely in the description of image index functions stated below. In the following, we identify stained pixels with the integer 1 and nonstained with 0 . The online Supplementary Material contains an example calculation of image indices (Section 1.1).

The dye coverage is a well-known index in dye tracer studies. It shows the proportion of stained pixels:

$$
I_{\mathrm{D}}(\vec{r})=\frac{1}{m} \sum_{i} r_{i},
$$

with $r_{i}$ being the $i$ th pixel in the row $\vec{r}$. We call (maximal) contiguous subvectors of equal values "runs." The runs of 1s represent the stained objects and their number is called the Euler number. Normalizing by the maximum number of possible runs (i.e., $m / 2$ ) gives:

$$
I_{\mathrm{E}}(\vec{r})=\frac{\left|\mathscr{R}_{1}(\vec{r})\right|}{\lceil m / 2\rceil},
$$

where $\mathscr{R}_{1}$ is a function that calculates the sequence of run lengths and the brackets $\lceil$ are the ceiling function that rounds up to the nearest integer. $I_{\mathrm{E}}(\vec{r})$ is small if the patterns contain only few stained objects and attains its maximum of 1 for a regular sequence of alternating stained and nonstained pixels.

The distribution of run lengths can be summarized in a robust manner by their $5 \%, 50 \%$, and $95 \%$ quantiles. In our experiments, however, we only used the $95 \%$ quantile, that we call the maximum run length, because it was more suitable than the other quantiles to distinguish between the different tillage managements:

$$
I_{\mathrm{Q} 0.95}=\frac{1}{m} \mathrm{Q}_{0.95}\left(\mathscr{R}_{1}(\vec{r})\right),
$$

where the function $Q_{p}$ calculates the $p$ th quantile. Furthermore, we can measure how fragmented the runs are by defining

$$
I_{\mathrm{F}}(\vec{r})=1-\frac{\left\langle\mathscr{R}_{1}(\vec{r}), \mathscr{R}_{1}(\vec{r})\right\rangle}{\left(\sum_{i} r_{i}\right)^{2}} .
$$

The indeterminate case where there are no stained pixels in a row and $I_{\mathrm{F}}=1-0 / 0$ is set to $0 . I_{\mathrm{F}}$ equals 0 for completely stained and nonstained image rows. Additionally, given two rows with the same amount of staining (i.e., equal $\left.I_{\mathrm{D}}\right) I_{\mathrm{F}}$ will be smaller for patterns with larger maximum run length $I_{\mathrm{Q} 0.95}$. The online Supplementary Material shows the variation of the fragmentation $I_{\mathrm{F}}$ for different dye coverages $I_{\mathrm{D}}$ and maximum width of stained objects $I_{\mathrm{Q} 0.95}$ (see Section 1.2 in Supplementary Material).

Last but not least, we want to evaluate the information contained in an image row $\vec{r}$ via the metric entropy, a version of Shannon's entropy. Shannon [28] defined the information content of an outcome $x$ of a discrete random variable as $h(x)=-\log _{2} p(x), p(x)$ being the probability of occurrence of the outcome $x$. It is measured in bits. The average information content (i.e., Shannon's entropy) is defined as

$$
H(X)=-\sum_{x \in X} p(x) \cdot \log _{2} p(x)
$$


for a set of events $X$ with probability of occurrence $p\left(x_{1}\right)$, $p\left(x_{2}\right), \ldots, p\left(x_{n}\right)$. Among all distributions with $n$ possible events, $H$ attains its maximum of $\log _{2} n$ for the uniform distribution. This is intuitively clear for the average information content is equivalent to our uncertainty about which event will occur. In other words, Shannon's entropy measures how much information is "produced" by the random variable. For an event that will certainly occur $H$ is equal to 0 .

To apply (6) to binary vectors, we consider individual bits as realisations of a binary random variable (i.e., possible outcomes are "stained" or "nonstained"). In this case $H$ is called the binary entropy function and attains its maximum for $p(1)=p(0)=0.5$. We replace the theoretical probabilities by empirical frequencies, $p(0)$ and $p(1)$, and calculate Shannon's entropy as

$$
H(\vec{r})=-\left(p(0) \cdot \log _{2} p(0)+p(1) \cdot \log _{2} p(1)\right) .
$$

More detailed structures can be captured by considering words of length $L$ of a binary vector. Then, Shannon's entropy is calculated based on the frequencies of these words. A normalization by $L$ yields the metric entropy

$$
I_{\mathrm{ME} L}(\vec{r})=\frac{1}{L} \cdot H\left(\mathscr{W}_{L}(\vec{r})\right),
$$

where $H$ is the generalisation of Shannon's entropy in (7) for words of length $L$. Particularly, the random variable $X$ from (6) is defined to pick an arbitrary word of length $L$ from $\vec{r}$. $\mathscr{W}_{L}$ is a sliding window function that moves through the image row $\vec{r}$ to produce the different words. The metric entropy gives useful values only if $m \gg L$. For our images we chose $L=8$. Compared to Shannon's entropy in (6), the metric entropy allows for assessing the correlation structure inside words. Indeed, metric entropy attains its maximum when single pixels in the words are uncorrelated and decrease for correlated pixels. For binary sequences $I_{\mathrm{ME} L}$ is confined to the interval $[0,1]$.

Special care should be taken when calculating image index functions for soils with an uneven soil surface. Actually, pixels not belonging to the soil should be excluded from the analysis. Therefore, to differentiate between soil and nonsoil on the ridged surface of $\mathrm{RT}, \mathrm{RT}_{\mathrm{pm}}$, and $\mathrm{RT}_{\mathrm{pm}+\text { crops }}$, we used the background binary images (Figure 1(b)). Areas identified as nonsoil were omitted. Additionally, we discarded the first and the last profiles completely because of edge effects and used 8 images for CT, RT, and $\mathrm{RT}_{\mathrm{pm}}$ and 5 images for $\mathrm{RT}_{\mathrm{pm}+\text { crops }}$. The image indices were calculated in R [29]. Figure SF3 in the online Supplementary Material shows a profile from $\mathrm{RT}_{\mathrm{pm}}$ with three different image indices.

\section{Results}

3.1. Properties of the Topsoils. The analysis of the topsoils revealed large differences between soils in the forest and on dryland fields (Table 2). Indeed, we found larger contents of $\mathrm{C}, \mathrm{N}$, and SOM (by a factor of 10) in the forest than in agricultural topsoils. Additionally, the clay fraction was more abundant and clay and silt together made up more than $50 \%$ of the soil fine fraction in the forest versus less than
TABLE 2: The average topsoil properties of 32 dryland fields and 16 forest sites in the Haean catchment.

\begin{tabular}{lcccc}
\hline \multirow{2}{*}{ Parameter } & \multicolumn{2}{c}{ Dryland sites } & \multicolumn{2}{c}{ Forest sites } \\
& Mean (\%) & Std. dev. (\%) & Mean (\%) & Std. dev. (\%) \\
\hline $\mathrm{N}$ & 0.06 & 0.02 & 0.41 & 0.17 \\
$\mathrm{C}$ & 0.53 & 0.30 & 5.77 & 2.47 \\
SOM $^{\mathrm{a}}$ & 0.98 & 0.53 & 9.92 & 4.25 \\
Clay & 5.43 & 2.98 & 12.27 & 4.87 \\
Silt & 22.32 & 7.10 & 38.81 & 9.79 \\
Sand & 72.26 & 9.97 & 48.91 & 14.01 \\
\hline
\end{tabular}

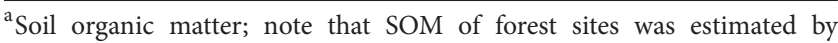
multiplying $\mathrm{C}$ by 1.72 .

$30 \%$ on the dryland fields. We consider the forest soils as essentially anthropogenically unaffected. Therefore, these differences underpin the strong anthropogenic transformation of agricultural soils in the former forested catchment.

These changes are also evident when comparing topsoil and subsoil properties of the experimental sites (Table 1). The allochthonous nature of these topsoils is reflected in the remarkable jump in texture. Indeed, the clay content increases from $2-8 \%$ up to approximately $21 \%$ from the topsoil (Ap and Ap1-Ap3) to the subsoil (2Apb).

\subsection{Dye Tracer Experiments}

3.2.1. Processes on Soil Surface and Soil Water Content. We observed the largest infiltration and the smallest runoff on CT (Table 3). However, the sediment load measured in runoff and the overall erosion were relatively high. The surface topography under RT decreased the amount of infiltrated water and increased the surface runoff. Concurrently, the erosion decreased compared to CT due to the barrier effect of the ridges. On $\mathrm{RT}_{\mathrm{pm}}$ the surface topography and plastic mulching of the ridges led to the largest surface runoff and soil erosion. Actually, approximately $50 \%$ of the irrigated water contributed to the runoff, and the erosion rate more than doubled compared to CT. Although the plastic mulching protected the soil in the ridges, the soil in the furrows was more susceptible to erosion due to the high runoff energy. By contrast, on $\mathrm{RT}_{\mathrm{pm}+\mathrm{crops}}$ the infiltration increased again and the surface runoff decreased to $31 \%$ probably due to the crop canopy. Indeed, the interception and the throughfall of irrigated water might have reduced the formation of surface runoff as well as the erosion potential.

At the beginning of the dye tracer experiment on CT the water content in $5 \mathrm{~cm}$ depth was lower compared to $20 \mathrm{~cm}$ depth (Figure 2). Approximately 15 minutes after the start of irrigation, the sensors placed in $5 \mathrm{~cm}$ depth registered an increase of water content, while the rise in $20 \mathrm{~cm}$ depth was delayed. Although the soil surface was even, the whole plot was inclined which explains larger soil moisture values measured by the FDRs situated downslope (FDR 2 and FDR 4).

On plots $\mathrm{RT}$ and $\mathrm{RT}_{\mathrm{pm}}$ we found larger water contents in furrows at the beginning of irrigation. This was probably caused by previously preferentially infiltrated water due to 
TABLE 3: Total amount of irrigation, infiltration, surface runoff, sediment load, and erosion during the dye tracer experiments.

\begin{tabular}{|c|c|c|c|c|c|c|c|}
\hline \multirow{2}{*}{ Experiment } & \multirow{2}{*}{ Total amount of irrigated water $(\mathrm{L})$} & \multicolumn{2}{|c|}{ Infiltration } & \multicolumn{2}{|c|}{ Runoff } & \multirow{2}{*}{ Sediment load (g) } & \multirow{2}{*}{ Erosion $\left(\mathrm{g} \mathrm{m}^{-2}\right)$} \\
\hline & & (L) & $(\%)$ & (L) & $(\%)$ & & \\
\hline $\mathrm{CT}^{\mathrm{a}}$ & 87 & 69 & 79 & 18 & 21 & 151.41 & 75.71 \\
\hline $\mathrm{RT}^{\mathrm{b}}$ & 74 & 46 & 62 & 28 & 38 & 66.59 & 33.30 \\
\hline $\mathrm{RT}_{\mathrm{pm}}{ }^{\mathrm{c}}$ & 81 & 41 & 50 & 41 & 50 & 322.45 & 161.23 \\
\hline $\mathrm{RT}_{\mathrm{pm}+\text { crops }}{ }^{\mathrm{d}}$ & 91 & 63 & 69 & 28 & 31 & 54.02 & 27.01 \\
\hline
\end{tabular}

${ }^{a}$ Conventional flat tillage, ${ }^{b}$ ridge tillage, ${ }^{c}$ ridge tillage with plastic mulch, ${ }^{d}$ ridge tillage with plastic mulch and potato crops.

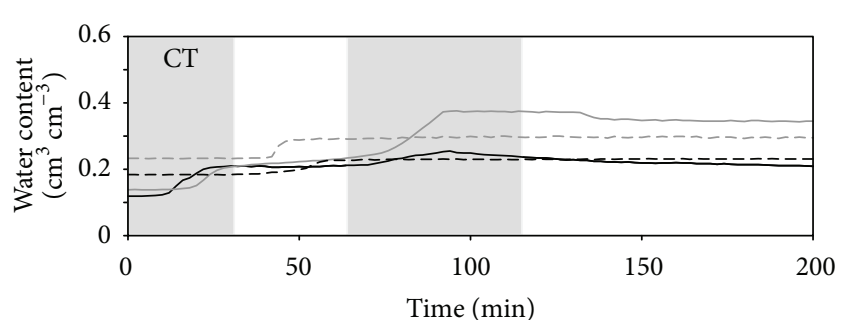

$\begin{array}{ll}- \text { FDR } 1 \text { ( } 5 \mathrm{~cm} \text { depth }) & --- \text { FDR } 3(20 \mathrm{~cm} \text { depth }) \\ \text { FDR } 2 \text { (5 cm depth) } & --- \text { FDR } 4(20 \mathrm{~cm} \text { depth })\end{array}$

(a)

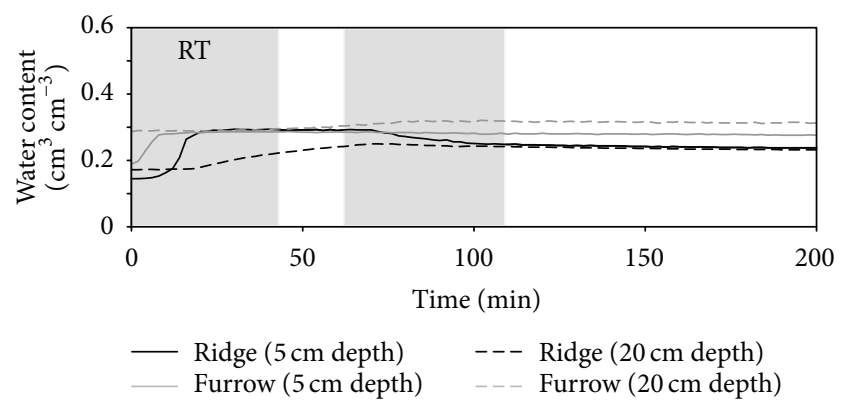

(b)

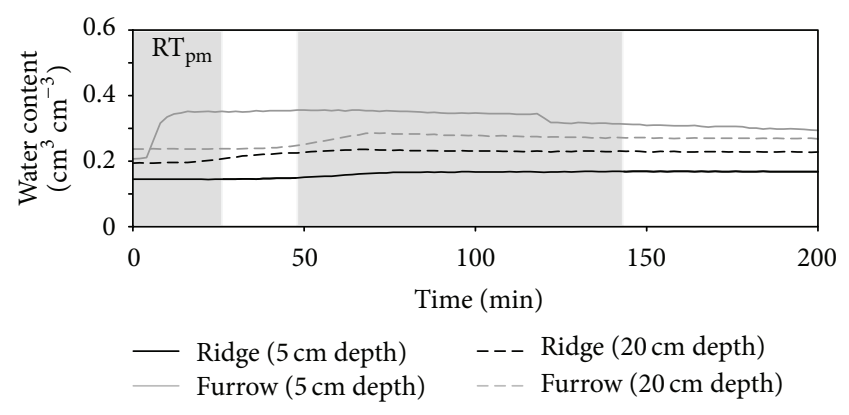

(c)

FIGURE 2: The dynamics of water content in different depths during the dye tracer experiments $\mathrm{CT}, \mathrm{RT}$, and $\mathrm{RT}_{\mathrm{pm}}$. The grey area indicates the time of irrigation.

topography effects. In $5 \mathrm{~cm}$ depth on RT the water content rose first in furrows, since the runoff from the ridges accumulated there and then in ridges. It increased only slightly in $20 \mathrm{~cm}$ depth.

During the irrigation on $\mathrm{RT}_{\mathrm{pm}}$ the dynamics of water content was comparable to RT except on ridges that were covered with plastic mulch. There, it increased slightly only in
$20 \mathrm{~cm}$ depth probably due to water which infiltrated primarily in the furrows and was subsequently funnelled laterally to the ridges.

3.2.2. Analysis of Flow Patterns. The dye tracer experiments revealed that firstly, tillage produced zones of preferential infiltration, namely, furrows and planting holes, and zones of no infiltration, namely, plastic mulched ridges (Figure 3). Therefore, the patchiness of the patterns and the occurrence of preferential flow are the result of the soil surface topography.

Secondly, the layer boundary between the spread topsoil and the subsoil was the most important feature for water movement in these agricultural soils. This was clearly shown by the decrease of all indices to zero in approximately $25-$ $35 \mathrm{~cm}$ depth (i.e., between the horizons Ap and Bwb on site 1 and between the horizons Ap1 and Ap2 on site 2, resp.) (Figure 4).

Thirdly, the shape of the index curves showed that in our experiments water flow occurred in the topsoil and was funnelled preferentially above the layer boundary. Actually, the vertical propagation to the deeper soil horizons via macropores, fissures, and cracks was absent. This was also confirmed by comparing the Brilliant Blue stained patterns to the iodide patterns. The propagation of the iodide tracer solution was similar to that of Brilliant Blue FCF.

The effect of the ridge topography can be best seen when comparing the indices $I_{\mathrm{F}}$ and $I_{\mathrm{Q} 0.95}$ on CT and RT. While the topsoil on CT was homogeneously stained, the patterns on RT consisted of alternating stained furrows, unstained parts on the sides of the ridges, and stained inner parts due to infiltration in planting holes (Figure 3). This was well reflected by a larger $I_{\mathrm{F}}(\max =0.87$ on RT versus $\max =0.73$ on CT $)$ and a smaller $I_{\mathrm{Q} 0.95}(\max =0.72$ on RT versus $\max =1.00$ on CT) that indicated more fractioned patterns with smaller stained objects on RT. The dye coverage $I_{\mathrm{D}}$ was large on both plots with its maximum being on the top of the soil profile. Due to the height of the ridges, $I_{\mathrm{D}}$ decreased slower on RT than on CT. Additionally, we calculated the smallest values of metric entropy $I_{\mathrm{ME} 8}$ near the soil surface because this part of the profile was homogeneously stained and the correlation between pixels inside the different words was large. Finally, in all four experiments $I_{\mathrm{E}}$ was approximately 0.1 , which is quite small and reflected the few stained objects.

The effect of the plastic mulch can be best extracted by comparing $I_{\mathrm{D}}$ and $I_{\mathrm{Q} 0.95}$ on RT and $\mathrm{RT}_{\mathrm{pm}}$. On RT, $I_{\mathrm{D}}$ was largest $(\max =1.00)$ on the soil surface as a result of 

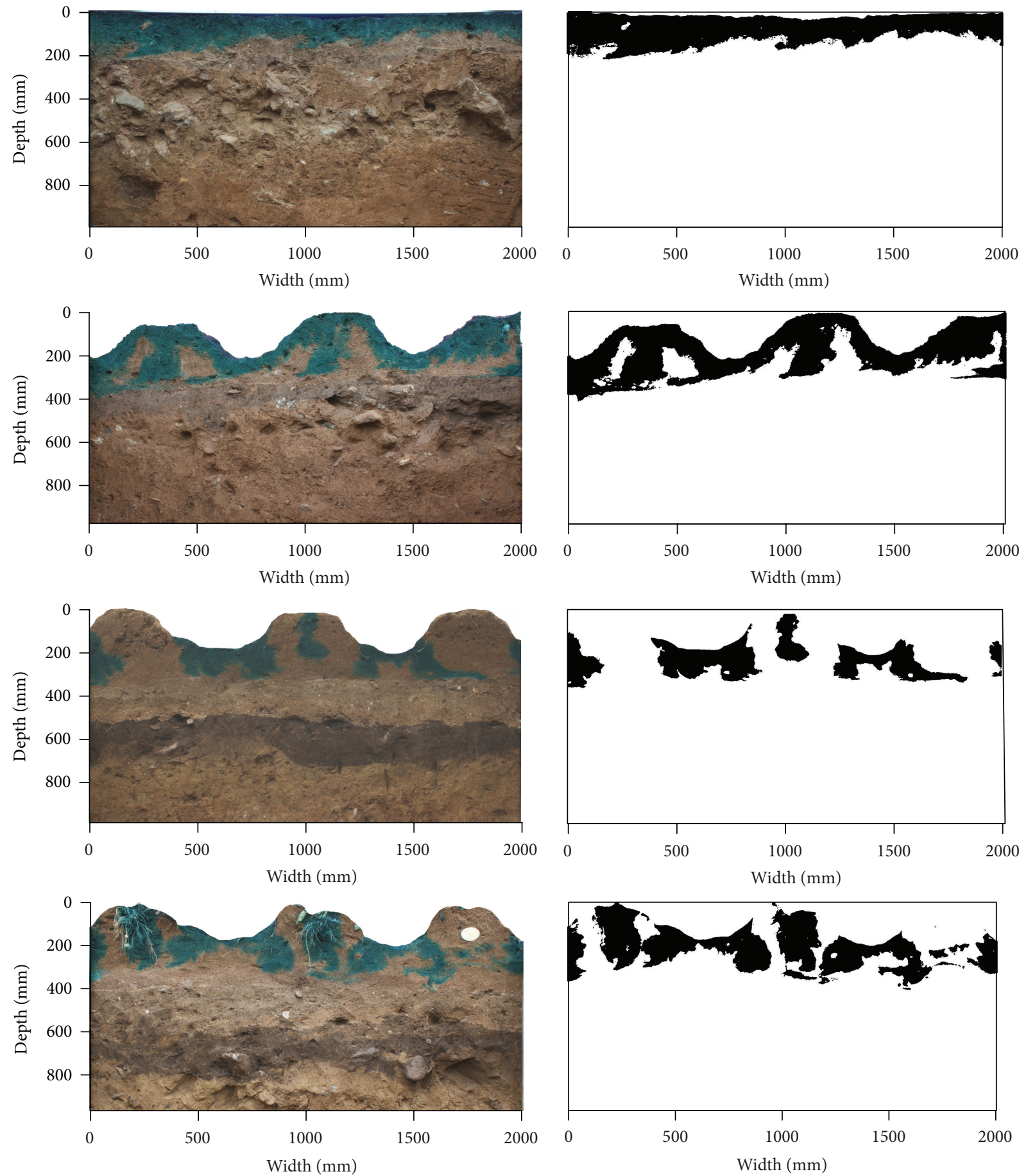

FIGURE 3: Example images of excavated soil profiles and their binary images. From top to bottom: CT, RT, RT $\mathrm{pm}_{\mathrm{m}}$, and $\mathrm{RT}_{\mathrm{pm}+\mathrm{crops}}$. Note that the slope orientation differs between field site 1 (CT and RT, slope oriented to the left) and field site 2 ( $\mathrm{RT}_{\mathrm{pm}}$ and $\mathrm{RT}_{\mathrm{pm}+\mathrm{crops}}$, slope oriented to the right). In the colour image of $\mathrm{RT}_{\mathrm{pm}+\text { crops }}$, the white object on the right hand ridge is a potato cut in half.

a homogeneous infiltration. In contrast, $I_{\mathrm{D}}$ on $\mathrm{RT}_{\mathrm{pm}}$ increased to a maximum of 0.53 in $20 \mathrm{~cm}$ depth indicating the large surface runoff from the plastic mulched ridges into furrows where most of the irrigated water infiltrated preferentially. Additionally, because the tracer could not infiltrate into the plastic covered ridges, the stained objects on $\mathrm{RT}_{\mathrm{pm}}$ were smaller as indicated by a decrease in $I_{\mathrm{Q} 0.95}$. In fact, the homogeneous matrix flow on RT at the soil surface was reflected by a large $I_{\mathrm{Q} 0.95}(\max =0.72)$, whereas the largest $I_{\mathrm{Q} 0.95}(\max =0.21)$ on $\mathrm{RT}_{\mathrm{pm}}$ marked the depth of the furrows and the laterally funnelled water above the layer boundary.

The effect of the root system on dye patterns was only slightly apparent in larger $I_{\mathrm{D}}$ in approximately $20 \mathrm{~cm}$ soil depth on $\mathrm{RT}_{\mathrm{pm}+\text { crops }}$ compared to $\mathrm{RT}_{\mathrm{pm}}$. The stem flow water 

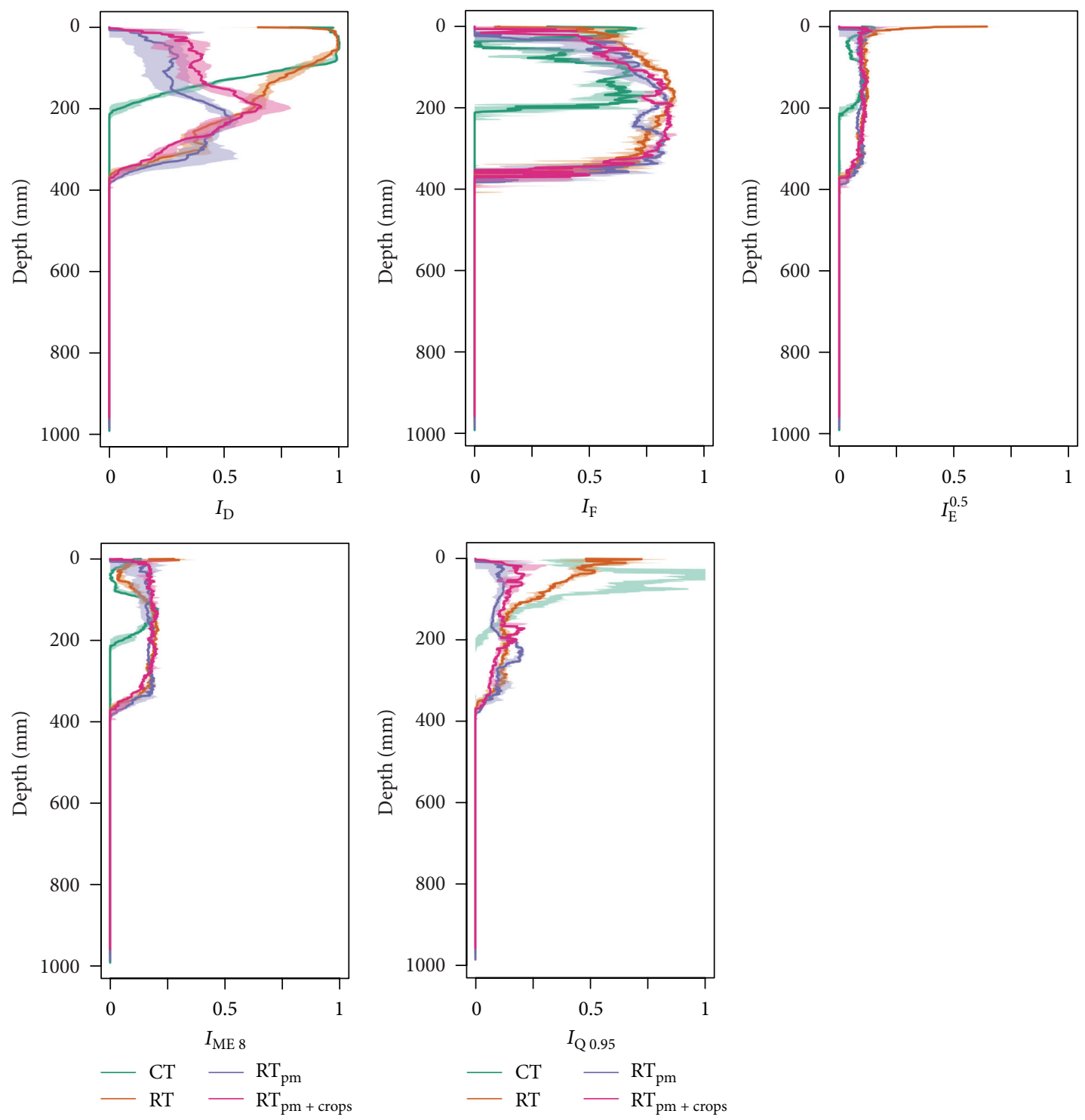

Figure 4: Image index functions and their $25 \%$ and $75 \%$ quantiles (colored areas): dye coverage $I_{\mathrm{D}}$, fragmentation $I_{\mathrm{F}}$, Euler number $I_{\mathrm{E}}$, metric entropy $I_{\mathrm{ME}}$, and maximum run length $I_{\mathrm{Q} 0.95}$. The Euler number $I_{\mathrm{E}}$ was scaled to enhance the details. The large values of $I_{\mathrm{E}}$ on RT near the soil surface are an artefact of the image processing.

primarily ponded in the planting holes. After infiltration the tracer solution flew preferentially along roots, which resulted in a maximum of $I_{\mathrm{D}}(0.66)$ in the root zone depth. In contrast, the maximum of $I_{\mathrm{D}}$ on $\mathrm{RT}_{\mathrm{pm}}$ without crop roots occurred in the depth of the furrows (0.53) and a less pronounced increase was visible in the depth of the layer boundary (in approximately $30 \mathrm{~cm}$ depth). Similarly, the largest $I_{\mathrm{Q} 0.95}$ reflected the infiltration in the furrows and the funnel flow above the layer boundary on $\mathrm{RT}_{\mathrm{pm}}$ $(0.22)$ and the highly stained root zone on $\mathrm{RT}_{\mathrm{pm}+\text { crops }}(0.25)$, respectively. Moreover, we observed another important factor which was best visible in the profile pictures (Figure 3). On $\mathrm{RT}_{\mathrm{pm}+\text { crops }}$ water movement in slope direction was no longer pronounced compared to $\mathrm{RT}_{\mathrm{pm}}$. Instead, water was primarily redirected upslope from furrows to ridges. We attributed this lateral flow to the hydraulic gradient between ridges and furrows. A similar situation was described by Ruidisch et al. [30] who found the lowest pressure heads in the inner part of the plastic mulched ridges due to root water uptake.

\section{Discussion}

4.1. The Effect of Tillage Management on Flow Processes. Ridge tillage and plastic mulching created typical infiltration zones (i.e., furrows and planting holes) and noninfiltration zones (i.e., plastic covered ridges) resulting in soil moisture differences between furrows and ridges. Our results agree well with Saffigna et al. [31] who investigated nonuniform infiltration patterns caused by hilling and potato canopy. They observed a higher soil moisture in furrows due to runoff from 
ridges. The runoff from ridges to furrows was also reported by Leistra and Boesten [32].

Additionally, we could show that ridge tillage and plastic mulching increased surface runoff and soil erosion substantially in the early growing season. The largest surface runoff and soil erosion under $\mathrm{RT}_{\mathrm{pm}}$ were confirmed by Arnhold et al. [33]. They combined field measurements with runoff collectors and a process-based modelling study using EROSION 3D to analyse the influence of ridge tillage and plastic mulch on soil erosion on two potato fields in the Haean catchment. These authors reported that in the later season the developed potato canopy could decrease surface runoff due to interception and throughfall. Moreover, a developed root system had the potential to interrupt the subsurface funnel flow above the layer boundary between the sandy topsoil, and the subsoil. Ruidisch et al. [30], for example, found in their combined tensiometer and modelling study that the coverage of the ridges and the root water uptake induced a pressure head gradient that forced the water to flow from wetter furrows to drier ridges. However, the potential for interrupting the lateral subsurface flow above the layer boundary depends presumably on the intensity and amount of rainfall. In our study we can relate the occurrence of the flow from furrows to ridges only to the irrigation rates which equalled moderate rain events of $37-45 \mathrm{~mm}$.

We want to highlight the former practice (that still takes place today occasionally) to distribute sandy soil material on agricultural fields prior to planting and the subsequent ploughing. Indeed, the distribution of sandy soil material to counterbalance erosion loss in the Haean catchment strongly influences the flow processes. This management practice created an artificial layering with different soil physical properties. A cohesive, denser, and finer textured subsoil is overlain by a topsoil consisting of a noncohesive and coarse material. As a result, an important textural boundary is created between the horizons. These structural differences between the topsoil and the subsoil are responsible for the funnel flow above the layer boundary. This was also reported by Petersen et al. [34] who found horizontal flow patterns due to soil layering with abrupt changes in soil structure induced by tillage.

Several authors reported that fissures, cracks, and earthworm burrows could act as preferential flow paths especially in fine textured subsoils $[16,35]$. Although ploughing activities lead to a discontinuity of macropores between topsoil and subsoil [36], macropores in the deeper subsoil can still conduct water [37]. In our experiments, we could not detect any macropore flow neither in the topsoil nor in the subsoil. This can be related to the fact that the noncohesive sandy toplayer lacks macropores even before ploughing. Moreover, we did not find any macropores like fissures or cracks, which could initiate preferential flow, in the denser and finertextured subsoil. Neither did we observe any soil burrowers on our sites, which could build a network of macropores.

4.2. Ecological Implications of the Agricultural Practice. Our results demonstrate that the risk of a vertical propagation of agrochemicals to groundwater is generally relatively low because of lack of macropores in the sandy soils. However, the lateral downhill water flow above the layer boundary between the anthropogenically modified topsoil and the subsoil seems to be ecologically relevant. Especially during the East Asian summer monsoon, when rainfall can reach more than $100 \mathrm{~mm}$ per day [22], the lateral flow through a coarse textured topsoil downhill may play a key role in the transport of agrochemicals. Thus, the field sites located next to the river system may represent locations for pollutants entering the water bodies.

We have shown that surface runoff, soil erosion, and subsurface water flow are reduced in the adult stage of the crop development. This also means that the leaching and erosion risk are especially high at the beginning of the growing season when the plants are juvenile and the fertilisers are recently applied. This is supported by Kettering et al. [38] who found the highest amounts of leached nitrate in a plastic mulched radish cultivation in the Haean catchment at the beginning of the growing season due to low interception and root water uptake.

However, in our experiments, the runoff still constituted one-third of the total irrigation even in the later season, when the crop canopy was well developed. We assume that the widespread usage of plastic mulching in combination with heavy monsoon events is partly responsible for higher phosphorus leaching in the Haean catchment because phosphorus is predominately transported via surface runoff. Kim et al. [9], for instance, reported that eutrophication and deterioration of water quality in downstream reservoirs in South Korea are associated with the discharge of phosphorus from agricultural dryland fields.

There are several options to reduce the risk of surface runoff and soil erosion. Arnhold et al. [33], for example, suggested reducing the herbicide application into furrows to allow for weed growth. This would increase surface roughness and, thus, enhance infiltration in furrows. The usage of perforated plastic mulch would be another conceivable option to reduce the runoff [30]. Wallace [39] recommended precision agriculture like better placement of fertiliser and a better timing of its application. Moreover, an adapted levelling, draining, and contouring could, in his opinion, lead to economic and environmental benefits. In a follow-up study Ruidisch et al. [40] simulated different scenarios of best management practices in a plastic mulched ridge cultivation system. They could show that fertiliser placement only in ridges as well as a better timing could considerably reduce the risk of nitrate leaching.

Finally, soil management in terms of a sustainable agriculture should improve the soil quality. This includes, for example, the enhancement of soil fertility and soil structure, soil carbon sequestration and the support of soil biota and bioturbation [5]. Our soil analysis showed that the spread sandy topsoils have a poor structure and a very low SOM content. Spreading of allochthonous soil material resulted in an unsustainable short-term agricultural management that still affects today's agriculture because additional large inputs of fertilisers are necessary to counterbalance the low SOM content of the soils. 
Hence, agricultural practices in the Haean catchment should aim now at long-term sustainable improvement of the degraded soils. This can be achieved by soil amendments like, for example, crop residues [5], biochar [41], and/or winter cover crops. These management practices could have several advantages. Biochar, for example, was proposed to enhance plant growth as well as to bind agrochemicals, which reduces phosphate and nitrate pollution of streams and groundwater. A notable retention of $\mathrm{N}$ on permeable soils under rainy conditions was pointed out as a further benefit of using biochar. Additionally, the amendment of biochar is assumed to support intensive sustainable agriculture and may thus reduce the necessity of further forest clearance [41]. Winter cover crops such as legumes could increase SOM in the topsoils, protect the field sites from soil erosion after harvest, and improve the nutrient status in the soils for the following season [42]. Thus, the cultivation of adequate winter cover crops can have multiple benefits in relation to soil and water quality.

\section{Conclusions}

A sustainable agriculture aims at both, increasing crop yield and minimizing the impact on natural resources. Therefore, to improve or at least to maintain the quality of water and soil is of great importance. When focusing on soil and water conservation, agricultural management practices should minimize runoff, control erosion and reduce nonpoint source pollution [5]. It is difficult to decide whether an agricultural practice is indeed sustainable because it has to fulfil several different criteria. However, it is easy to decide that it is nonsustainable if it fails to fulfil one of them. A repeated distribution of infertile sandy soil on agricultural fields in order to compensate soil loss is obviously a short-term nonsustainable practice. Even though this management is nowadays only occasionally practised, the resulting anthropogenic soils should be protected from further degradation.

In our study we found that the impact of ridge cultivation with or without plastic mulch on the subsurface water flow is relatively low compared to the increase in surface runoff. Therefore, to reduce it, we suggest (i) to encourage crop production in ridge cultivation with perforated biodegradable plastic mulch and (ii) to enhance infiltration in furrows by either minimizing herbicide input into furrows or by protecting the furrows with crop residues. These practices will diminish the risk of erosion and leaching of agrochemicals, especially in the early season when crops are juvenile. Perforated plastic mulch can still maintain a positive effect on crop yield by increasing the temperature in the root zone and by weed control.

Furthermore, a particular attention should be paid to the risk of lateral downhill leaching of agrochemicals and fertilisers induced by artificial layering, especially on field sites located directly next to the stream network. Thus, we propose (iii) to promote the establishment of riparian buffer zones between dryland farming fields and the rivers.

Moreover, a sustainable long-term development of fertile topsoils by protection from erosion and return of organic material is necessary. Therefore, we suggest further research (iv) to identify the potential of soil amendments such as biochar to improve the soil carbon stock in sandy soils under monsoonal conditions and (v) to identify appropriate species of winter cover crops that could increase the SOM content of topsoils and protect the bare soil from erosion and leaching after the harvest in the autumn and winter season.

\section{Acknowledgments}

The aurhors are grateful to Professor Baltasar Trancón y Widemann for technical assistance and intensive discussions. They would like to thank Andreas Kolb for his invaluable technical support and Bora Lee and Heera Lee for translation and negotiating permissions for their experiments. Furthermore the authors would like to thank all TERRECO members, who helped them with soil sampling and Professor Ok and his laboratory assistants for analysing the topsoil samples. This study was carried out as part of the International Research Training Group TERRECO (GRK 1565/1) funded by the Deutsche Forschungsgemeinschaft (DFG) at the University of Bayreuth, Germany, and the Korean Research Foundation (KRF) at Kangwon National University, Chuncheon, South Korea.

\section{References}

[1] D. Tilman, J. Fargione, B. Wolff et al., "Forecasting agriculturally driven global environmental change," Science, vol. 292, no. 5515, pp. 281-284, 2001.

[2] D. Tilman, K. G. Cassman, P. A. Matson, R. Naylor, and S. Polasky, "Agricultural sustainability and intensive production practices," Nature, vol. 418, no. 6898, pp. 671-677, 2002.

[3] V. H. Dale and S. Polasky, "Measures of the effects of agricultural practices on ecosystem services," Ecological Economics, vol. 64, no. 2, pp. 286-296, 2007.

[4] H. Godfray, "Food security: the challenge of feeding 9 billion people," Science, vol. 327, pp. 812-818, 2010.

[5] R. Lal, "Soils and sustainable agriculture. A review," Agronomy for Sustainable Development, vol. 28, no. 1, pp. 57-64, 2008.

[6] J. H. J. Spiertz, "Nitrogen, sustainable agriculture and food security. A review," Agronomy for Sustainable Development, vol. 30, no. 1, pp. 43-55, 2010.

[7] R. Lal, "Laws of sustainable soil management," Agronomy for Sustainable Development, vol. 29, no. 1, pp. 7-9, 2009.

[8] A. M. Saveda and W. Shaw, Eds., South Korea: A Country Study, GPO for the Library of Congress, 1990.

[9] B. Kim, J.-H. Park, G. Hwang, M.-S. Jun, and K. Choi, "Eutrophication of reservoirs in South Korea," Limnology, vol. 2, no. 3, pp. 223-229, 2001.

[10] S. J. Hwang, S. K. Kwun, and C. G. Yoon, "Water quality and limnology of korean reservoirs," Paddy and Water Environment, vol. 1, pp. 43-52, 2003.

[11] G. Kim, S. Chung, and C. Lee, "Water quality of runoff from agricultural-forestry watersheds in the geum river basin, Korea," Environmental Monitoring and Assessment, vol. 134, no. 1-3, pp. 441-452, 2007.

[12] J. Hendrickx and M. Flury, "Uniform and preferential flow mechanisms in the vadose zone," in Conceptual Models of Flow 
and Transport in the Fractured Vadose Zone, N. R. Council, Ed., National Academy Press, Washington, DC, USA, 2001.

[13] C. Bogner, D. Gaul, A. Kolb, I. Schmiedinger, and B. Huwe, "Investigating flow mechanisms in a forest soil by mixed-effects modelling," European Journal of Soil Science, vol. 61, no. 6, pp. 1079-1090, 2010.

[14] T. J. Gish, D. Gimenez, and W. J. Rawls, "Impact of roots on ground water quality," Plant and Soil, vol. 200, no. 1, pp. 47-54, 1998.

[15] J. Šimůnek, N. J. Jarvis, M. T. Van Genuchten, and A. Gärdenäs, "Review and comparison of models for describing non-equilibrium and preferential flow and transport in the vadose zone," Journal of Hydrology, vol. 272, no. 1-4, pp. 14-35, 2003.

[16] S. Bachmair, M. Weiler, and G. Nützmann, "Controls of land use and soil structure on water movement: lessons for pollutant transfer through the unsaturated zone," Journal of Hydrology, vol. 369, no. 3-4, pp. 241-252, 2009.

[17] N. J. Jarvis, "A review of non-equilibrium water flow and solute transport in soil macropores: principles, controlling factors and consequences for water quality," European Journal of Soil Science, vol. 58, no. 3, pp. 523-546, 2007.

[18] W. Lament, "Plastic mulches for the production of vegetable crops," HortTechnoloqy, vol. 3, no. 1, pp. 35-39, 1993.

[19] S. Kim, J. Yang, C. Park, Y. Jung, and B. Cho, "Effects of winter cover crop of ryegrass(lolium multiflorum) and soil conservation practices on soil erosion and quality in thesloping uplands," Journal of Applied Biological Chemistry, vol. 55, pp. 2228, 2007.

[20] G. Lee, J. Lee, J. Ryu et al., "Status and soil management problems of highland agriculture of the main mountainous region in the south korea," in Proceedings of the 19th World Congress of Soil Science, R. J. Gilkes and N. Prakongkep, Eds., Soil solutions for a changing world, International Union of Soil Sciences, 2010.

[21] R. P. C. Morgan, Soil Erosion and Conservation, Blackwell, Malden, Mass, USA, 2005.

[22] J.-H. Park, L. Duan, B. Kim, M. J. Mitchell, and H. Shibata, "Potential effects of climate change and variability on watershed biogeochemical processes and water quality in Northeast Asia," Environment International, vol. 36, no. 2, pp. 212-225, 2010.

[23] lUSS Working Group WRB, "World reference base for soil resources 2006-a frame-work for international classification, correlation and communication," World Soil Resources Reports 103, FAO, Rome, Italy, 2006, ftp://ftp.fao.org/agl/agll/docs/wsrr103e.pdf.

[24] M. Flury and H. Fluhler, "Tracer characteristics of brilliant blue FCF," Soil Science Society of America Journal, vol. 59, no. 1, pp. 22-27, 1995.

[25] J. $\mathrm{Lu}$ and L. Wu, "Visualizing bromide and iodide water tracer in soil profiles by spray methods," Journal of Environmental Quality, vol. 32, no. 1, pp. 363-367, 2003.

[26] C. Steger, M. Ulrich, and C. Wiedemann, Machine Vision Algorithms and Applications, John Wiley \& Sons, Weinheim, Germany, 2008.

[27] B. Trancón y Widemann and C. Bogner, "Image analysis for soil dye tracer infiltration studies," in Proceedings of the $3 \mathrm{rd}$ International Conference on Image Processing Theory, Tools and Applications, pp. 409-414, 2012.

[28] C. E. Shannon, "A mathematical theory of communication," Bell System Technical Journal, vol. 27, pp. 379-423, 1948.
[29] R Core Team, R: A Language and Environment for Statistical Computing, R Foundation for Statistical Computing, Vienna, Austria, 2012, http://www.r-project.org/.

[30] M. Ruidisch, J. Kettering, S. Arnhold, and B. Huwe, "Modeling water flow in a plastic-mulched ridge cultivation system on hillslopes affected by South Korean summer monsoon," Agricultural Water Management, vol. 116, pp. 204-217, 2013.

[31] P. G. Saffigna, C. B. Tanner, and D. R. Keeney, "Non-uniform infiltration under potatocanopies caused by interception, stemflow, and hilling," Agronomy Journal, vol. 68, no. 2, pp. 337-342, 1976.

[32] M. Leistra and J. J. T. I. Boesten, "Pesticide leaching from agricultural fields with ridges and furrows," Water, Air, and Soil Pollution, vol. 213, no. 1-4, pp. 341-352, 2010.

[33] S. Arnhold, M. Ruidisch, S. Bartsch, C. Shope, and B. Huwe, "Simulation of run patterns and soil erosion on mountainous farmland with and without plastic covered ridgefurrowcultivation in South Korea," Transactions of the ASABE, vol. 56, no. 2, pp. 667-679, 2013.

[34] C. T. Petersen, S. Hansen, and H. E. Jensen, "Depth distribution of preferential flow patterns in a sandy loam soil as affected by tillage," Hydrology and Earth System Sciences, vol. 4, pp. 769776, 1997.

[35] M. Weiler and F. Naef, "An experimental tracer study of the role of macropores in infiltration in grassland soils," Hydrological Processes, vol. 17, no. 2, pp. 477-493, 2003.

[36] B. Gjettermann, K. L. Nielsen, C. T. Petersen, H. E. Jensen, and S. Hansen, "Preferential flow in sandy loam soils as affected by irrigation intensity," Soil Technology, vol. 11, no. 2, pp. 139-152, 1997.

[37] C. Bogner, M. Mirzaei, S. Ruy, and B. Huwe, "Microtopography, water storage and flow patterns in a fine-textured soil under agricultural use," Hydrological Processes, vol. 27, no. 12, pp. 1797$1806,2012$.

[38] J. Kettering, M. Ruidisch, C. Gaviria, Y. Ok, and Y. Kuzyakov, "Fate of fertilizer ${ }^{15} \mathrm{~N}$ in intensive ridge cultivation with plastic mulching under a monsoon climate," Nutrient Cycling in Agroecosystems, vol. 95, pp. 57-72, 2013.

[39] A. Wallace, "High-precision agriculture is an excellent tool for conservation of natural resources," Communications in Soil Science and Plant Analysis, vol. 25, pp. 45-49, 1994.

[40] M. Ruidisch, S. Bartsch, J. Kettering, B. Huwe, and S. Frei, “The effect of fertilizer bestmanagement practices on nitrate leaching in a plastic mulched ridge cultivation system," Agriculture, Ecosystems and Environment, vol. 169, pp. 21-32, 2013.

[41] C. J. Barrow, "Biochar: potential for countering land degradation and for improving agriculture," Applied Geography, vol. 34, pp. 21-28, 2012.

[42] S. M. Dabney, J. A. Delgado, and D. W. Reeves, "Using winter cover crops to improve soil and water quality," Communications in Soil Science and Plant Analysis, vol. 32, no. 7-8, pp. 1221-1250, 2001. 

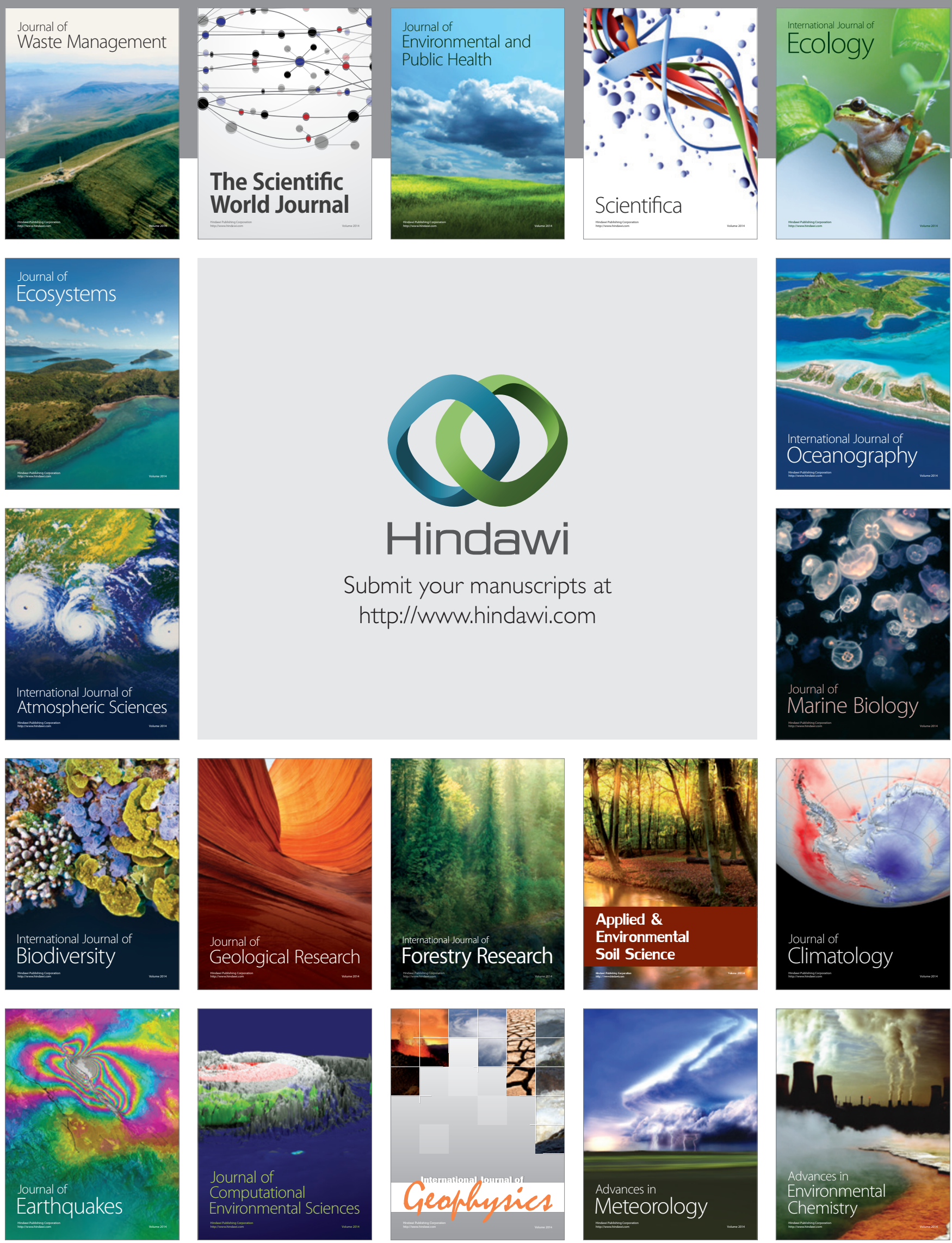